\title{
Incidence and cohort prevalence for autism spectrum disorders in the Avalon Peninsula, Newfoundland and Labrador
}

\author{
Lorine Pelly MD, Cathy Vardy MD, Bridget Fernandez MD, Leigh Anne Newhook MD MSc, Roger Chafe PhD
}

\section{Abstract}

Background: Recent studies have reported increased prevalence for autism spectrum disorders in a number of geographical locations. Our objective was to determine the incidence and 1-year cohort prevalence for autism spectrum disorders in children less than 15 years of age and living in the Avalon Peninsula at the time of diagnosis.

Methods: Retrospective and prospective data were obtained from the Janeway Children's Health and Rehabilitation Centre (St. John's), including the identification and specific diagnosis for all children assessed for autism spectrum disorder from 2006 to 2010. Additional clinic data were reviewed to update the data until the end of 2013.

Results: From 2006 to 2010, 272 children had a diagnosis of autism spectrum disorder, averaging 54 new cases per year. The incidence of new cases increased from 10.1 to 16.7 cases per 10000 per year from 2006 to 2010 . At the end of 2013, the prevalence among children born in 2006 was 1 case of autism spectrum disorder per 46 children or 215.77 per 10000.

Interpretation: We found higher rates of autism spectrum disorder than previously reported for this population. The prevalence in this region is also high when compared with other global populations. The high rate of diagnosis supports the need for a provincial autism spectrum disorder registry and further research on autism spectrum disorder within this population.

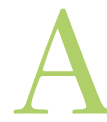

utism spectrum disorders are a set of neurodevelopmental disorders associated with restrictive or repetitive behaviours and difficulties with verbal and interpersonal communication..$^{1,2}$ Although the cause of autism spectrum disorders is unknown, it appears to be multifactorial, with both environmental factors and a significant genetic component playing roles. ${ }^{3,4}$ The population of the Avalon Peninsula in Newfoundland and Labrador has been shown to have a unique genetic make-up related to its founder population, with higher rates of certain conditions with a genetic cause..$^{5-7}$ Other studies involving this pediatric population also found some of the highest global rates of type 1 diabetes mellitus, ${ }^{8,9}$ which has been hypothesized to have a possible association with autism. ${ }^{10} \mathrm{We}$ felt it would be useful to determine the incidence and prevalence for autism spectrum disorder in this part of the world. Our study is one of only a few studies that have presented the incidence and prevalence data for autism spectrum disorder in any part of the Canadian population, ${ }^{11-15}$ although work is underway to create a national autism database. ${ }^{16}$

The primary aim of our study was to review the incidence rate of autism spectrum disorder among children living in the Avalon Peninsula at the time of diagnosis over a 5 -year period (2006-2010). We also used the available data to determine the prevalence of autism spectrum disorder for the cohort of children born between Jan. 1, 2006, and Dec. 31, 2006, up to Dec. 31,2013 . Our secondary objectives included examining the patient characteristics in children with autism spectrum disorder in the Avalon Peninsula, and evaluating some of the diagnostic tests performed and the referral patterns among these patients.

\section{Methods}

\section{Study population}

The study included all children living in the Avalon Peninsula between 2006 and 2010. This region is Statistic Canada's Census Division No. 1, Newfoundland and Labrador. ${ }^{17}$ In addition to the unique genetic make-up of this population, the Avalon Peninsula was selected because it is a well-defined geographic area, which encompasses over $50 \%$ of the population of New-

Competing interests: None declared.

This article has been peer reviewed.

Correspondence to: Lorine Pelly, pellyl@myumanitoba.ca

CMAJ Open 2015. DOI:10.9778/cmajo.20140056 
foundland and Labrador and for whom high-quality clinical assessment data were available. The study involved patients with a diagnosis of autism spectrum disorder by the Department of Child Development at the Janeway Children's Health and Rehabilitation Centre (St. John's), a part of the Eastern Health regional health authority. This department is the only child development centre in the region and is the only centre giving comprehensive autism spectrum disorder diagnoses to patients in this region. Although this department treats children from across the province, children were identified as being from the Avalon Peninsula if they were living in a community in Census Division No. 1 at the time of diagnosis. Because autism spectrum disorder is almost always diagnosed in childhood, we defined the population at risk as children less than 15 years of age.

\section{Design}

We first calculated the incidence rate by year for a 5 -year period between 2006 and 2010. We then used the identified cases to calculate the prevalence of autism spectrum disorder in the cohort born in 2006. Finally, a chart review was conducted on all confirmed cases identified between 2006 and 2010. A standardized data abstraction form was developed and was piloted on 10 charts. The form was then revised, and data were abstracted from the remaining charts. The data collected included basic demographic information, categorization of the type of autism spectrum disorder, comorbidities, type of testing used to diagnose the condition and some of the referral patterns for the cases.

\section{Sources of data}

This study used data obtained from the Department of Child Development at the Janeway Children's Health and Rehabilitation Centre. We included patients with a diagnosis of nonsyndromic autism spectrum disorder confirmed by a multidisciplinary team and who fit the DSM-IV-TR definition of one of the autism spectrum disorders, less than 15 years of age, and living in the Avalon Peninsula at the time of diagnosis. Diagnoses were confirmed through multiple observations, consultation with a developmental pediatrician, a detailed patient history and, in most instances, the use of at least one module of the Autism Diagnostic Observational Schedule. ${ }^{18}$ Patients who did not fit the diagnostic criteria and those with a diagnosis of another genetic syndrome that may also have symptoms of autism spectrum disorder were excluded. In most instances, patients were seen on a continuing basis by the department after their diagnosis, which further alleviated concerns about misdiagnosis. Patients were first identified from an autism spectrum disorder register maintained by the department from 2005 to 2011. We included all new diagnoses identified from Jan. 1, 2006, to Dec. 31, 2010, to allow for the collection of data for complete years. This list of patients was then compared with the office records of patients with autism spectrum disorder maintained by each developmental pediatrician in the department to identify any discrepancies and to ensure no patients meeting the inclusion criteria were missed. Although not included in the original chart abstraction, we used depart- ment data to ascertain subsequent patients with a diagnosis of autism spectrum disorder who met the 2006 cohort inclusion criteria for the period up to Dec. 31, 2013.

\section{Statistical analysis}

We calculated incidence by taking the number of new cases diagnosed each year and dividing them by the population for the region aged less than 15 years (the population at risk). We did not have access to data for each specific year for the population at risk within the region. We performed a range of sensitivity analyses around the exact population number to use; overall, the population was fairly stable over the period so that variations in calculating the at-risk population did not have a great effect on the reported prevalence or incidence. We used a midpoint estimate for the population at risk, calculated by averaging the census population aged $0-14$ years in $2006^{19}$ with that population in $2011,{ }^{20}$ resulting in a population of 39498. There were no population estimates available that included information on age and sex at the level of census divisions; therefore, no calculations were made for incidence based on these characteristics.

We examined the cohort prevalence for all children born in 2006. The numerator was all children in this cohort with a diagnosis of autism spectrum disorder by Dec. 31, 2010, and the denominator was the average number of children aged 4 and 5 years reported in the 2011 Canada Census. ${ }^{20}$. The denominator was calculated in this manner because children born in 2006 would have been 4 or 5 years of age during data collection for the 2011 Canada Census. ${ }^{20}$ The population data used to calculate incidence and prevalence are reported in Appendix 1 (available at www.cmajopen.ca/content/3/3/ E276/suppl/DC1). We updated the prevalence rate in this cohort using data until the end of 2013. Confidence intervals (95\% CIs) were generated for prevalence and incidence based on the Poisson error structure. Descriptive analysis and $\chi^{2}$ analysis were performed on other demographic data using Stata Statistical Software, Release 9 (College Station, Texas).

\section{Ethics approval}

This study was reviewed and approved by Newfoundland and Labrador's Health Research Ethics Authority.

\section{Results}

Between 2006 and 2010, 272 new cases of autism spectrum disorder were diagnosed within the study population (Table 1). Median age at diagnosis was 3.84 years (interquartile range [IQR] 2.76-6.19). Of these 272 patients, 234 were male (male:female ratio $=6 \cdot 2: 1$ ). When diagnoses specific to autism spectrum disorder were evaluated, $74(27.2 \%)$ patients had autistic spectrum disorder, 130 (47.8\%) had autistic disorder, $56(20.6 \%)$ had Asperger syndrome and 12 (4.4\%) had pervasive developmental disorder-not otherwise specified. Although not a specific DSM-IV-TR definition, autism spectrum disorder was a common classification given within the department in absence of a more specific diagnosis. There was no significant variation in specific diagnosis based on year of diagnosis $\left(\chi^{2}\right.$ test, 


\section{OPEN}

Research

Table 1: Characteristics of patients with a diagnosis of ASD, aged 0-14 yr, living in the Avalon Peninsula, Newfoundland and Labrador

\begin{tabular}{|c|c|}
\hline Characteristic & $\begin{array}{l}\text { No. of patients (\%) } \\
\quad n=272\end{array}$ \\
\hline \multicolumn{2}{|l|}{ Sex } \\
\hline Male & $234(86.0)$ \\
\hline Female & $38(14.0)$ \\
\hline \multicolumn{2}{|l|}{ Age at diagnosis, yr } \\
\hline $0<1$ & $0 \quad(0.0)$ \\
\hline $1<2$ & $10 \quad(3.7)$ \\
\hline $2<3$ & $77(28.3)$ \\
\hline $3<4$ & $57(21.0)$ \\
\hline $4<5$ & $33(12.1)$ \\
\hline $5<7$ & $43(15.8)$ \\
\hline $7<11$ & $44(16.2)$ \\
\hline $11<15$ & $8 \quad(2.9)$ \\
\hline \multicolumn{2}{|l|}{ Specific diagnosis } \\
\hline ASD & $74(27.2)$ \\
\hline $\mathrm{AD}$ & $130(47.8)$ \\
\hline Asperger syndrome & $56(20.6)$ \\
\hline PDD-NOS & $12(4.4)$ \\
\hline \multicolumn{2}{|c|}{ Autism diagnostic observational schedule } \\
\hline Yes & $269(98.9)$ \\
\hline No & $3 \quad(1.1)$ \\
\hline \multicolumn{2}{|c|}{ Autism diagnostic observational schedule module $(n=269)$} \\
\hline 1 & $112(41.6)$ \\
\hline II & $75(27.9)$ \\
\hline III & $82(30.5)$ \\
\hline IV & $0 \quad(0.0)$ \\
\hline \multicolumn{2}{|l|}{ Genetics referral } \\
\hline Yes & $193(71.0)$ \\
\hline No & $1(0.4)$ \\
\hline Unknown & $78(28.6)$ \\
\hline \multicolumn{2}{|l|}{ Neuroimaging } \\
\hline Yes & $79(29.0)$ \\
\hline No & $185(68.0)$ \\
\hline Unknown & $8 \quad(3.0)$ \\
\hline \multicolumn{2}{|c|}{ Provincial autism program referral } \\
\hline Yes & $195(71.7)$ \\
\hline No & $75(27.6)$ \\
\hline Unknown & $2(0.7)$ \\
\hline Seizures & $14 \quad(5.1)$ \\
\hline Birthmarks & $14 \quad(5.1)$ \\
\hline Congenital anomalies & $16 \quad(5.9)$ \\
\hline Developmental regression & $23(8.5)$ \\
\hline Behavioural issues & $28(10.3)$ \\
\hline Dietary restrictions or issues & 17 (6.3) \\
\hline Sleep disturbance & $13(4.8)$ \\
\hline Gl symptomatology & $12(4.4)$ \\
\hline Anxiety & $25 \quad(9.2)$ \\
\hline OCD & 9 (3.3) \\
\hline Depression & $0 \quad(0.0)$ \\
\hline ADHD & $27 \quad(9.9)$ \\
\hline Other & $19 \quad(7.0)$ \\
\hline $\begin{array}{l}\text { Note: } A D=\text { autistic disorder, } A D H D \\
\text { autism spectrum disorder, } \mathrm{GI}=\text { ga } \\
\text { PDD-NOS = persuasive developm }\end{array}$ & $\begin{array}{l}\text { ractivity disorder, ASD = } \\
\text { sessive compulsive, } \\
\text { wise specified. }\end{array}$ \\
\hline
\end{tabular}

$p=0.784)$. At least one module of the Autism Diagnostic Observational Schedule ${ }^{18}$ was completed for 269 of the 272 patients (98.9\%). Module I was used for diagnosis in 112 (41.6\%) patients. Of the 272 patients with a diagnosis, 195 (71.7\%) were referred to the Provincial Intensive Applied Behavioural Analysis Program, which is available to children up to grade 3; 79 (29.0\%) were referred for neuroimaging; and 193 $(71.0 \%)$ were referred for genetics follow-up. Our review found that many patients had at least one of the comorbidities often associated with autism; the most prevalent were behavioural issues $(n=28)$, attention-deficit/hyperactivity disorder $(n=27)$ and anxiety disorder $(n=25)$. The yearly incidence for 2006 was 10.1 per 10000 (95\% CI, 7.7-14.4), increasing to 16.7 per 10000 (95\% CI, 13.3-21.8) by 2010 (Table 2). There was a statistically significant difference between the yearly incidence in 2006 and in $2010(p=0.01)$.

Cohort prevalence for children born in 2006 was calculated at the end of 2010, including children between 4 and less than 5 years old. Out of an estimated cohort population of 2668 children based on 2011 Canada Census data, some form of autism spectrum disorder was diagnosed in 33 of these children, giving an overall prevalence of 123.4 per 10000 or 1 in 81 (95\% CI, 1 in 56 to 1 in 113). The cohort prevalence for children aged 4 years at the end of 2010 was also calculated based on sex. The cohort prevalence of autism spectrum disorder in males was 1 in 46 (95\% CI, 1 in 31 to 1 in 65). The cohort prevalence for females was 1 in 431 (95\% CI, 1 in 147 to 1 in 2091). Although not included in the original chart abstraction, we obtained data from the Department of Child Development to ascertain the number of subsequent patients with a diagnosis of autism spectrum disorder who met the 2006 cohort inclusion criteria. In 2011, 9 additional children met the cohort inclusion criteria, 3 patients met the criteria in 2012 and 13 patients met the criteria in 2013. With the inclusion of these patients, a total of 58 patients had a diagnosis of autism spectrum disorder in the 2006 cohort, for an overall prevalence of 215.77 per 10000 or 1 in 46.

\section{Interpretation}

We found a high rate of diagnosis of autism spectrum disorder in children living in the Avalon Peninsula. The incidence of new cases of autism spectrum disorder increased signifi-

Table 2: Number of new ASD diagnoses in patients aged 0-14 yr in the Avalon Peninsula, Newfoundland and Labrador

\begin{tabular}{|lcc|}
\hline Year & $\begin{array}{c}\text { No. of cases } \\
n=272\end{array}$ & $\begin{array}{c}\text { Incidence per } 10 \text { 000 population } \\
(95 \% \mathrm{Cl})\end{array}$ \\
\hline 2006 & 40 & $10.1(7.2-13.7)$ \\
\hline 2007 & 50 & $12.7(9.4-16.7)$ \\
\hline 2008 & 54 & $13.7(10.3-17.8)$ \\
\hline 2009 & 62 & $15.7(12.0-20.1)$ \\
\hline 2010 & 66 & $16.7(12.9-21.3)$ \\
\hline Note: Denominator $=39498$ (average of census populations in 2006 and 2011). \\
\hline
\end{tabular}


cantly between 2006 and 2010. By the end of 2013, the cohort born in 2006 had one of the highest prevalence rates ever reported for a population in Canada. Approximately 70\% of patients were referred to the provincially funded Intensive Applied Behavioural Analysis program or for genetic followup and $29 \%$ for neuroimaging exams. There were a range of comorbidities also reported in this population, including behavioural issues, attention-deficit/hyperactivity disorder and anxiety disorder.

Our estimation of prevalence in a particular age cohort is similar to the method used by the Autism and Developmental Disabilities Monitoring Network in the United States ${ }^{21}$. This US Network used a survey of a cohort of children 8 years of age and reported a cohort prevalence ranging from 57 to 219.14 per 10000 in 2010. Because of the timeline of our study and available data, we used a cohort of children 7 years of age at the end of 2013. Our cohort prevalence was 215.77 per 10000 , which is at the high end of the range of the US survey. Similarly, the rates of autism spectrum disorder in the Avalon Peninsula are higher compared with other prevalence studies. For example, a review of 43 studies of the prevalence for autism spectrum disorder that have been published since 1966 found an average prevalence of $60-70$ per $10000 .{ }^{22}$ The prevalence in our cohort (215.77 per 10000$)$ was over 3 times higher than the median prevalence (62 per 10000$)$ reported in a systematic review in $2012 .{ }^{23}$ Other studies have found that boys are more likely to have an autism spectrum disorder than girls, with male-to-female ratios ranging from $2: 1$ to $6.5: 1 .^{24}$ We found a male-to-female ratio of 6.2:1, which is at the high end of this previously reported range.

Of particular interest is a report with data collected in Newfoundland and Labrador that calculated prevalence rates for the entire province for some of the same period covered by our study. ${ }^{15}$ They followed a 2 -year birth cohort, born in 2000-2001, up to 2008. They reported a prevalence rate of $61.8 / 10000$ at 4-5 years of age and 94.2/10 000 at 6-7 years of age. One reason for the difference between the 2 studies may be that the other study used cases ascertained from "agencies that provide services to children with autism." 15 Our study found that only $72.4 \%$ of diagnosed cases were referred to the provincial program for these services. The reasons for this relatively low referral rate are unknown, but it may be related to cognitive impairment being either too mild or too severe, parental choice, age of diagnosis or some other barrier to access. A study involving a cohort of children in Nova Scotia reported a similar level of agreement $(69.1 \%)$ between data for autism spectrum disorder diagnoses obtained directly from clinical departments and data captured from wider administrative sources. ${ }^{25}$ The exact reason for the difference between the data reported by Ouellette-Kuntz and colleagues and our data would have to be determined by a comparison of the 2 datasets. This incongruence points to the difficulty of getting accurate prevalence data, particularly when relying on administrative datasets, and may support the need to create a registry from multiple sources to ensure that all cases of autism spectrum disorder in the region are being captured.

\section{Strengths and limitations}

This study has a number of strengths. First, it evaluated a well-defined geographic area with a fairly stable pediatric population. There is only one pediatric development clinic for the area to which almost all children suspected of having an autism spectrum disorder are referred, which assisted in the identification of cases. We identified cases of autism spectrum disorder based on detailed patient histories, and observations and clinical assessments of a multidisciplinary team that included a developmental pediatrician. Most of the cases (98.6\%) were confirmed using at least one module of the Autism Diagnostic Observational Schedule. ${ }^{18}$ In their review of autism spectrum disorder prevalence studies, Elsabbagh and colleagues found only 1 other prevalence study that used the Autism Diagnostic Observational Schedule, which is considered the clinical gold standard for diagnosing autism spectrum disorder, ${ }^{25}$ as the primary method of case identification. ${ }^{23}$ For these reasons, our study was able to capture a large proportion of children with autism spectrum disorders requiring clinical supervision for a defined population.

Because of the small population studied, changes in the number of new cases identified had a substantial impact on the prevalence rates. For example, the addition of 25 cases for 2011-2013 increased the cohort prevalence rate from 123.4 to 215.77 cases per 10000 . We were limited to the information on the patient chart for recording the comorbidities and firstorder family connections, which may have underreported the influence of these factors. Although the population appeared relatively stable, we were not able to capture specific changes in the underlying population, in terms of patient emigration and immigrations to the region, which may have impacted the calculation of prevalence and incidence. The prevalence and incidence rates determined in the study do not reflect possible rates in other geographic locations.

\section{Conclusion}

This study adds to the data on the incidence and prevalence of autism spectrum disorder in Canada. It also points to the need to establish improved methods of tracking autism spectrum disorder to ensure that the health burden of the condition is accurately measured. The resources required to enhance opportunities for children with autism spectrum disorder extend into both health and education, which are both provincial responsibilities.

\section{References}

1. Diagnostic and statistical manual of mental disorders. Fifth edition. Arlington (VA): American Psychiatric Publishing; 2013.

2. Rapin I, Tuchman RF. Autism: definition, neurobiology, screening, diagnosis. Pediatr Clin North Am 2008;55:1129-46.

3. Heil KM, Schaaf CP. The genetics of autism spectrum disorder - A guide for clinicians. Curr Psychiatry Rep 2013;15:334.

4. Handrigan GR, Chitayat D, Lionel AC, et al. Deletions in $16 \mathrm{q} 24.2$ are associated with autism spectrum disorder, intellectual disability and congenital renal malformation. 7 Med Genet 2013;50:163-73.

5. Sun G, Cahill F, Gulliver W, et al. Concordance of BAI and BMI with DXA in the Newfoundland population. Obesity (Silver Spring) 2013;21:499-503.

6. Mahoney K, Buckley D, Alam M, et al. High incidence of pediatric idiopathic epilepsy is associated with familial and autosomal dominant disease in eastern Newfoundland. Epilepsy Res 2012;98:140-7.

7. Eng B, Greenlay B, Waye JS. Characterisation of the British alpha 0-thalassaemia deletion: evidence of a founder effect in Newfoundland, Canada. Br 7 Haematol 2009;147:150-2. 
8. Newhook LA, Curtis J, Hagerty D, et al. High incidence of childhood type 1 diabetes in the Avalon Peninsula, Newfoundland, Canada. Diabetes Care 2004; 27:885-8.

9. Newhook LA, Penney S, Fiander J, et al. Recent incidence of type 1 diabetes mellitus in children 0-14 years in Newfoundland and Labrador, Canada climbs to over 45/100 000: a retrospective time trend study. BMC Res Notes 2012;5:628.

10. Freeman SJ, Roberts W, Daneman D. Type 1 diabetes and autism: Is there a link? Diabetes Care 2005;28:925-6.

11. Bryson SE, Clark BS, Smith IM. First report of a Canadian epidemiological study of autistic syndromes. 7 Child Psychol Psychiatry 1988;29:433-45.

12. Ouellette-Kuntz H, Coo H, Yu CT, et al. Prevalence of pervasive developmental disorders in two Canadian provinces. 7 Policy Pract Intellect Disabil 2006;3: 164-72.

13. Fombonne E, Zakarian R, Bennett A, et al. Pervasive development disorders in Montréal, Quebec, Canada: prevalence and links with immunizations. Pediatrics 2006;118:e139-e150.

14. Lazoff T, Zhong L, Piperni T, et al. Prevalence of pervasive development disorders among children at the English Montréal School Board. Can 7 Psychiatry 2010;55:715-20.

15. Ouellette-Kuntz H, Coo H, Lam M, et al. The changing prevalence of autism in three regions of Canada. 7 Autism Dev Disord 2014;44:120-36.

16. Ouellette-Kuntz H, Coo H, Yu CT, et al. Status report - National Epidemiologic Database for the Study of Autism in Canada (NEDSAC). Chronic Dis Inj Can 2012;32:84-9.

17. Census Division No. 1, Newfoundland and Labrador [map]. Ottawa: Statistics Canada. Available: www12.statcan.ca/datasets/Rp-eng.cfm?TABID=4\&LANG= $\mathrm{E} \& \mathrm{~A}=\mathrm{R} \& \mathrm{APATH}=3 \& \mathrm{DETAIL}=0 \& \mathrm{DIM}=0 \& \mathrm{FL}=\mathrm{A} \& \mathrm{FREE}=0 \& \mathrm{GC}=1001 \& \mathrm{GID}$ $=906056 \& \mathrm{GK}=2 \& \mathrm{GRP}=1 \& \mathrm{O}=\mathrm{D} \& \mathrm{PID}=102010 \& \mathrm{PRID}=0 \& \mathrm{PTYPE}=101955 \& \mathrm{~S}=$ $0 \&$ SHOWALL $=0 \&$ SUB $=0 \&$ Temporal $=2011 \&$ THEME $=88 \&$ VID $=0 \&$ VNAMEE $=\& \mathrm{VNAMEF}=\& \mathrm{D} 1=0 \& \mathrm{D} 2=0 \& \mathrm{D} 3=0 \& \mathrm{D} 4=0 \& \mathrm{D} 5=0 \& \mathrm{D} 6=0($ accessed 2015 July 15).

18. Lord, C, Rutter, M, Goode, S, et al. Autism Diagnostic Observation Schedule: a standardized observation of communicative and social behavior. 7 Autism Dev Disord 1989;19:185-212.

19. 2006 Census of Canada: topic-based tabulations. Age groups (14) and sex (3) for the population of Canada, provinces, territories, census divisions and census subdivisions, 2006 Census - Division No. 1 [table]. Ottawa: Statistics Canada. Available: www.arcticstat. org/Table.aspx/Region/[Canada][Labrador]Census_Division_no._11/Indicator/ [Population]Age/2010-08-12-02/13846 (accessed 2015 Apr. 7).

20. 2011 Census of Canada: topic-based tabulations. Age groups (131) and sex (3) for the population of Canada, provinces, territories, census divisions and census subdivisions, 2011 Census - Division No. 1. Ottawa: Statistics Canada. Avail- able: www12.statcan.gc.ca/datasets/Rp-eng.cfm?TABID=2\&LANG=E\&A=R\& APATH $=3 \&$ DETAIL $=0 \&$ DIM $=0 \& \mathrm{FL}=\mathrm{A} \& \mathrm{FREE}=0 \& \mathrm{GC}=1001 \& \mathrm{GID}=90605$ $6 \& \mathrm{GK}=2 \& \mathrm{GRP}=1 \& \mathrm{O}=\mathrm{D} \& \mathrm{PID}=102010 \& \mathrm{PRID}=0 \& \mathrm{PTYPE}=101955 \& \mathrm{~S}=0 \&$ SHOWALL $=0 \&$ SUB $=0 \&$ Temporal $=2011 \&$ THEME $=88 \&$ VID $=0 \&$ VNAMEE $=\& \mathrm{VNAMEF}=\& \mathrm{D} 1=0 \& \mathrm{D} 2=0 \& \mathrm{D} 3=0 \& \mathrm{D} 4=0 \& \mathrm{D} 5=0 \& \mathrm{D} 6=0($ accessed 2015 July 15).

21. Prevalence of autism spectrum disorder among children aged 8 years - Autism and Developmental Disabilities Monitoring Network, 11 Sites, United States, 2010. MMWR Surveill Summ 2014;63:1-21.

22. Fombonne E. Epidemiology of pervasive developmental disorders. Pediatr Res 2009;65:591-8.

23. Elsabbagh M, Divan G, Koh YJ, et al. Global prevalence of autism and other pervasive development disorders. Autism Res 2012;5:160-79.

24. Johnson CP, Myers SM; Council on Children with Disabilities. Identification and evaluation of children with autism spectrum disorders. Pediatrics 2007;120: $1183-215$.

25. Dodds L, Spencer A, Shea S, et al. Validity of autism diagnoses using administrative health data. Chronic Dis Can 2009;29:102-7.

Affiliations: Section of Pediatric Infectious Diseases (Pelly), Pediatrics and Child Health, University of Manitoba, Winnipeg, Man.; Discipline of Pediatrics (Vardy, Newhook, Chafe), Faculty of Medicine, Memorial University of Newfoundland, St. John's, NL; Discipline of Genetics (Fernandez), Faculty of Medicine, Memorial University of Newfoundland, St. John's, NL

Contributors: Lorine Pelly, Leigh Anne Newhook, Cathy Vardy, and Bridget Fernandez developed the concept and design of the research. Lorine Pelly and Roger Chafe collected data. Lorine Pelly, Leigh Anne Newhook, Cathy Vardy and Roger Chafe analyzed and interpreted the data. Lorine Pelly and Roger Chafe drafted the manuscript. All of the authors gave final approval of the version to be published and agreed to be guarantors of the work.

Acknowledgements: This project was supported by funding from the Janeway Children's Hospital Foundation. Thanks to Jeff Dowden for reviewing the data analysis.

Supplemental information: For reviewer comments and the original submission of this manuscript, please see www.cmajopen.ca/content/3/3/ E276/suppl/DC1 